\title{
The pattern of atopic dermatitis in a group of patients attending two private clinics in Erbil city
}

\begin{tabular}{|c|c|c|}
\hline \multicolumn{2}{|l|}{ Received: 3/ 6/ 2018} & Accepted: 21/ 10/ 2018 \\
\hline Ban Anton Bahnan ${ }^{1}$ & Sherzad Abdulahad Shabu²* & Siham Tahir Amedi ${ }^{1}$ \\
\hline \multicolumn{3}{|c|}{ Abstract } \\
\hline \multicolumn{3}{|c|}{$\begin{array}{l}\text { Background and objective: Atopic dermatitis is a chronic, relapsing inflammatory } \\
\text { disease of the skin. It is a common disease that primarily affects young children. It results } \\
\text { from complex interactions between genetic susceptibility genes. This study aimed to } \\
\text { assess atopic dermatitis among the affected cases, mainly in terms of age and gender } \\
\text { distribution, and its clinical and laboratory findings. }\end{array}$} \\
\hline \multicolumn{3}{|c|}{$\begin{array}{l}\text { Methods: A descriptive cross sectional study was carried out in two private clinics in Erbil } \\
\text { city. A convenience sampling method was used to recruit } 70 \text { study participants who were } \\
\text { clinically examined by the investigator. A questionnaire was specially designed for } \\
\text { interviewing these patients. The diagnosis was made on the clinical ground. Patients were } \\
\text { also sent for blood investigations and a skin swab for microscopic examination. }\end{array}$} \\
\hline \multicolumn{3}{|c|}{$\begin{array}{l}\text { Results: The mean } \pm \text { SD of the participants' age was } 20.57 \pm 17.94 \text { years. Females } \\
\text { constituted } 68.6 \% \text { of the participants. More than } 64 \% \text { of the patients had generalized body } \\
\text { lesions, } 54.3 \% \text { had a positive family history of atopic dermatitis, and } 48.5 \% \text { had a history of } \\
\text { other atopic diseases. The majority }(58.3 \%) \text { of those aging less than two years had } \\
\text { face lesions while the majority ( } 74.4 \%) \text { of the patients aging more than } 15 \text { years had } \\
\text { generalized body lesions, and this was statistically significant. }\end{array}$} \\
\hline \multicolumn{3}{|c|}{$\begin{array}{l}\text { Conclusion: Atopic dermatitis affects a wide age group, and different age categories have } \\
\text { different sites of the lesion. Family history is a prominent feature of the disease. Clinically, } \\
\text { lichenification is more among older age groups compared to the eczematous lesion, which } \\
\text { is more among younger age groups. }\end{array}$} \\
\hline
\end{tabular}

Keywords: Atopic dermatitis; Assessment; Erbil city.

\section{Introduction}

Atopic dermatitis $(A D)$ is a chronic, relapsing inflammatory disease of the skin. It is a common disease that primarily affects young children. The inherited tendency of the human body to produce immunoglobulin $\mathrm{E}(\lg \mathrm{E})$ antibodies as a response to some common proteins from the environment like pollen, house dust mites, and some food allergens is called Atopy. ${ }^{1}$ AD is considered to be a severe inflammatory and pruritic dermatological disease which is a result of complex interactions between genetic susceptibility genes resulting in a defective skin barrier, defects in the innate immune system, and increased immunologic responses to allergens and microbial antigens. ${ }^{2}$ The downregulation of cornified envelope genes (filaggrin and loricrin), reduced ceramide levels, increased levels of endogenous proteolytic enzymes, and enhanced transepidermal water loss result in a marked decrease in skin barrier function which associated with $\mathrm{AD} .^{3}$ Around one-fifth of all people are affected by $A D$ during their lifetime. The prevalence of the disease greatly varies throughout the world. ${ }^{4}$ Globally, it is estimated that the prevalence of $A D$ is $15-20 \%$ and $1-3 \%$ among children and adults, respectively. It is also estimated that the incidence of the

${ }^{1}$ Department of Medicine, College of Medicine, Hawler Medical University, Erbil, I raq.

${ }^{2}$ Department of Community Medicine, College of Medicine, Hawler Medical University, Erbil, I raq

* Correspondence: sherzad.hakim@hmu.edu.krd 
disease has increased twice or trice during the last few decades, especially in industrialized countries. ${ }^{5}$ The main findings of $A D$ may include xerosis, lichenification, and eczematous lesions. Depending on the patient's age, different locations of the patient's body show eczematous changes of different morphology. $A D$ is clinically presented with pruritis and eczema, which are the essential features of the disease. The typical morphological and age-specific patterns may affect the face, neck, extensor areas in children, flexural areas in any age group, excluding axillary and groin regions. Other important features which support the diagnosis of $A D$ could be the early age of onset, personal or family history of Atopy, and xerosis. ${ }^{6}$ The diagnosis of $A D$ is mainly made clinically, and it depends on the historical features of the disease. The morphological features, skin lesions' distribution, and the associated clinical signs also play a crucial role in the diagnosis. ${ }^{7}$ Elevated levels of immunoglobin $E(\lg E)$ and circulating eosinophils are also some associated laboratory abnormalities of the $A D$, but the diagnosis is mainly based on personal/ family history of atopy and physical examination by excluding other conditions. ${ }^{8}$ Atopic dermatitis is a common skin inflammatory disease that poses a significant burden on patients' quality of life. To improve the general knowledge about such disease, this study aimed at assessing atopic dermatitis among the affected cases, mainly in terms of its age and gender distribution, and its clinical and laboratory findings.

\section{Methods}

This descriptive cross sectional study was carried out in two private clinics in Erbil city, the capital of Iraqi Kurdistan, from August to December 2017. A convenience sampling method was used to recruit 70 study participants who were clinically examined by the investigator. A questionnaire was specially designed for interviewing these patients, which included questions on some socio-demographic criteria of the studied sample like age, sex, and occupation, besides some other relevant questions like the first onset of the disease and sites of the lesions. The data on family history of related diseases like atopic dermatitis, asthma, rhinoconjunctivitis, and food allergy were also collected. The diagnosis was made on the clinical ground, and all patients were sent to undergo some blood investigations like Leptin hormone, lipid profile, and IgE level. In addition, a swab was taken from the skin lesion for microscopic examination. Microsoft Excel 2010 and the statistical package for the social sciences (version 20) were used for data summarization and data analysis. The Chi-square test was used to identify any association between different variables in the study. A $P$ value of $\leq 0.05$ was considered to be statistically significant. Ethical approval was obtained from the Research Ethics Committee of the College of Medicine, Hawler Medical University. Verbally informed consents were obtained from the participants who were assured about the anonymity of the study.

\section{Results}

Of the 70 patients who participated in this study, $27.1 \%$ were between 16-25 years old, $21.4 \%$ were between 26-35 years, and $17.2 \%$ were between $2-5$ years. The mean \pm SD of the participants' age was $20.57 \pm 17.94$ years, with a minimum age of four months and a maximum of 73 years. Females constituted $68.6 \%$ of the participants, and the majority of participants $(91.4 \%)$ were of urban residence, as shown in Table 1. Concerning the sites of the lesions, $64.3 \%$ of the participants had generalized body lesions, $17.1 \%$ had trunk lesions, $11.4 \%$ had face lesions, and $7.1 \%$ had extremities involvement. The age of onset of the disease in more than one fifth of the sample was 7-20 years and also less than one year of age, followed by 1-2 years of age $(12 \%)$. The mean \pm SD of the participants' age of onset of the disease 
was $8.30 \pm 10.05$ years. The majority weight, followed by obese $(32.8 \%)$, and $(38.6 \%)$ of the participants were of normal overweight $(18.6 \%)$, as shown in Table 2.

Table 1: The socio-demographic characteristics of the studied sample.

\begin{tabular}{lcc}
\hline Variable & Frequency & Percentage \\
\hline Age in years & & \\
$<2$ & 8 & $(11.4)$ \\
$2-5$ & 12 & $(17.2)$ \\
$6-15$ & 10 & $(14.3)$ \\
$16-25$ & 19 & $(27.1)$ \\
$26-35$ & 15 & $(21.4)$ \\
$\geq 36$ & 6 & $(8.6)$ \\
Gender & & \\
Male & 22 & $(31.4)$ \\
Female & 48 & $(68.6)$ \\
Address & & \\
Urban & 64 & $(91.4)$ \\
Rural & 6 & $(8.6)$ \\
\hline
\end{tabular}

Table 2: The lesion sites, age of onset of the disease and weight status of the studied sample.

\begin{tabular}{lcc}
\hline Characteristic & Frequency & Percent \\
\hline Site of the lesion & 8 & $(11.4)$ \\
Face & 12 & $(17.1)$ \\
Trunk & 5 & $(7.1)$ \\
Extremities & 45 & $(64.3)$ \\
Generalized & & \\
Age of first onset & 22 & $(31.4)$ \\
$<1$ & 12 & $(17.1)$ \\
$1-2$ & 6 & $(8.6)$ \\
$3-6$ & 22 & $(31.4)$ \\
$7-20$ & 8 & $(11.4)$ \\
$>20$ & & \\
Body mass index & 7 & $(10)$ \\
Underweight & 27 & $(38.6)$ \\
Normal weight & 13 & $(18.6)$ \\
Overweight & 23 & $(32.8)$ \\
Obese & 70 & $(100)$ \\
Total & & \\
\hline
\end{tabular}


The majority $(98.6 \%)$ of the studied sample of other atopic diseases $(67.6 \%$ had had pruritis, followed by xerosis $(95.7 \%)$, lichenification $(70 \%)$, eczematous lesions $(58.6 \%)$, and associated bacterial and viral infection (31.4\% and $8.6 \%)$ respectively. Almost half of the participants had a history allergic rhinitis, $11.8 \%$ had asthma, and $20.6 \%$ had both). Also, $54.3 \%$ of the sample had a family history of atopic dermatitis, as shown in Table 3.

Table 3: Associated features, history of other atopic diseases and family history of atopic dermatitis

\begin{tabular}{|c|c|c|}
\hline Associated factor & Frequency & Percent \\
\hline \multicolumn{3}{|l|}{ Pruritis } \\
\hline No & 1 & $(1.4)$ \\
\hline Yes & 69 & $(98.6)$ \\
\hline \multicolumn{3}{|l|}{ Lichenification } \\
\hline No & 21 & $(30)$ \\
\hline Yes & 49 & $(70)$ \\
\hline \multicolumn{3}{|l|}{ Xerosis } \\
\hline No & 3 & $(4.3)$ \\
\hline Yes & 67 & $(95.7)$ \\
\hline \multicolumn{3}{|l|}{ Eczematous lesion } \\
\hline No & 29 & $(41.4)$ \\
\hline Yes & 41 & $(58.6)$ \\
\hline \multicolumn{3}{|c|}{ Associated viral infection } \\
\hline No & 64 & $(91.4)$ \\
\hline Yes & 6 & $(8.6)$ \\
\hline \multicolumn{3}{|c|}{ Associated bacterial infection } \\
\hline No & 48 & $(68.6)$ \\
\hline Yes & 22 & $(31.4)$ \\
\hline \multicolumn{3}{|c|}{ History of atopic diseases } \\
\hline No & 36 & $(51.4)$ \\
\hline Yes & 34 & $(48.5)$ \\
\hline \multicolumn{3}{|c|}{ If Yes, what disease? } \\
\hline Asthma & 4 & $(11.8)$ \\
\hline Allergic rhinitis & 23 & $(67.6)$ \\
\hline Both & 7 & $(20.6)$ \\
\hline \multicolumn{3}{|c|}{ Family history of atopic dermatitis } \\
\hline No & 32 & $(45.7)$ \\
\hline Yes & 38 & $(54.3)$ \\
\hline
\end{tabular}


Concerning hormonal and other years old for whom we had no lipid biochemical investigations, $60 \%$ of the studied sample had a high level of Leptin hormone, $64.3 \%$ had a high IgE level. Excluding those who were under two profile, $10 \%$ of the sample had a high cholesterol level, $8.6 \%, 2.8 \%$, and $1.4 \%$ had a high triglyceride, HDL and LDL level, respectively as shown in Table 4.

Table 4: Hormonal and other biochemical markers assessment of the studied sample.

\begin{tabular}{|c|c|c|}
\hline Marker & Frequency & Percent \\
\hline \multicolumn{3}{|c|}{ Leptin hormone } \\
\hline Normal & 28 & $(40)$ \\
\hline High & 42 & $(60)$ \\
\hline \multicolumn{3}{|l|}{$\lg E$} \\
\hline Normal & 25 & $(35.7)$ \\
\hline High & 45 & (64.3) \\
\hline \multicolumn{3}{|c|}{ Triglyceride } \\
\hline Normal & 44 & (62.9) \\
\hline High & 6 & (8.6) \\
\hline Missing* & 20 & $(28.6)$ \\
\hline \multicolumn{3}{|c|}{ Cholesterol } \\
\hline Normal & 43 & $(61.4)$ \\
\hline High & 7 & $(10)$ \\
\hline Missing* & 20 & $(28.6)$ \\
\hline \multicolumn{3}{|l|}{ HDL } \\
\hline Normal & 48 & $(68.6)$ \\
\hline High & 2 & $(2.8)$ \\
\hline Missing* & 20 & $(28.6)$ \\
\hline \multicolumn{3}{|l|}{ LDL } \\
\hline Normal & 49 & (70) \\
\hline High & 1 & (1.4) \\
\hline Missing* & 20 & $(28.6)$ \\
\hline
\end{tabular}

* Investigations were not done for these cases because of their young age (less than 2 years) 
The participants were further divided into three age groups; <2 years, $2-12$, and $\geq 13$ years. The association between these three different age categories and a number of other variables was studied. The study revealed a significant association between participants' age and their lesion's site, with $58.3 \%$ of less than two years group had face lesion, $74.4 \%$, and $53.3 \%$ of those aging $\geq 13$ and $2-12$ years, respectively had generalized lesions. A significant association was also found with lichenification, as $81.4 \%$ of those aging $\geq 13$ years had lichenification and
$33.3 \%$ of those aging $<2$ years. A significant association was also found with the existing of eczematous lesion since $91.7 \%$ of those aging $<2$ years had such a lesion compared to $73.3 \%$ and $44.2 \%$ for those aging 2-12 years and $\geq 13$ years, respectively. No significant association was found with xerosis, as shown in Table 5 . The study also revealed a significant statistical association between Leptin and IgE levels. More than $75 \%$ of those patients having a high level of Leptin had elevated IgE level too, $24.4 \%$ had normal lgE level, as shown in Table 6.

Table 5: Association between the age of participants and site of the lesion, presence of lichenification, xerosis, and eczematous lesion.

\begin{tabular}{lcccc}
\hline Lesion characteristics & $\begin{array}{c}\text { Age in years } \\
\text { No (\%) }\end{array}$ & $\begin{array}{c}\mathbf{2}-15 \text { years } \\
\text { No (\%) }\end{array}$ & $\begin{array}{c}>\text { 15 years } \\
\text { No (\%) }\end{array}$ & P value \\
\hline Site of the lesion & $7(58.3)$ & $1(6.7)$ & $0(0)$ & \\
Face & $0(0)$ & $2(13.3)$ & $10(23.31)$ & \\
Trunk & $0(0)$ & $4(26.7)$ & $1(2.3)$ & $<0.001$ \\
Extremities & $5(41.7)$ & $8(53.3)$ & $32(74.4)$ & \\
Generalized & & & & \\
Lichenification & $8(66.7)$ & $5(33.3)$ & $8(18.6)$ & \\
No & $4(33.3)$ & $10(66.7)$ & $35(81.4)$ & 0.005 \\
Yes & $1(8.3)$ & $0(0)$ & $2(4.7)$ & \\
Xerosis & $11(91.7)$ & $15(100)$ & $41(95.3)$ & 0.559 \\
No & & & & \\
Yes & $1(8.3)$ & $4(26.7)$ & $24(55.8)$ & \\
Eczematous Lesion & $11(91.7)$ & $11(73.3)$ & $19(44.2)$ & 0.005 \\
No & $12(100)$ & $15(100)$ & $43(100)$ & \\
Yes & & & & \\
Total & & & \\
\hline
\end{tabular}

Table 6: Association between Leptin hormone and IgE levels.

\begin{tabular}{lcccc}
\hline Leptin level & $\begin{array}{c}\text { Normal } \\
\text { No (\%) }\end{array}$ & $\begin{array}{c}\text { IgE level } \\
\text { High } \\
\text { No (\%) }\end{array}$ & $\begin{array}{c}\text { Total } \\
\text { No (\%) }\end{array}$ & $P$ value \\
\hline Normal & $15(53.6)$ & $13(46.4)$ & $28(100)$ & 0.013 \\
High & $10(24.4)$ & $32(75.6)$ & $42(100)$ & \\
\hline
\end{tabular}




\section{Discussion}

Atopic dermatitis is a chronic eczematous dermatitis characterized by having diverse clinical features and a high prevalence. Many different hypotheses were suggested about its pathogenesis, but its cause remained not fully understood. Understanding of its clinical features may help in clarifying the pathogenesis of the disease. ${ }^{9}$ The study revealed that the mean \pm SD of the participants' age was $20.57 \pm$ 17.94 years. Patients aging $16-25$ years constituted $27.1 \%$ of the sample followed by $21.4 \%$ for those aged $26-35$ years, $17.2 \%$ for those aged $2-5$ years, $14.3 \%$ for those aged $6-15$ years, and $11.4 \%$ were less than two years old. These results were to some extent consistent with those of a study conducted in Seoul, Korea which revealed that the majority $(37.7 \%)$ were between 19-30 years old, followed by $11-18$ years $(24 \%), 3-10$ years $(20.8 \%)$ and less than two years $(4.1 \%) .{ }^{9} \mathrm{~A}$ study conducted in Japan revealed that $38.7 \%$ of the participants were between $20-29$ years followed by $0-9$ years (23.4\%), $10-19$ years $(21.8 \%)$ and 30 years and older $(16.1 \%) .^{10}$ Regarding the age of onset, $31.4 \%$ of the patients had the disease when they were less than one year old, and a similar proportion was reported for those aging 7-20 years, followed by $1-2$ years $(17.1 \%)$, 20 years and older $(11.4 \%)$, and $3-6$ years $(8.6 \%)$. While the Korean study revealed that $30 \%$ of the participants had an age of onset of 7-18 years, followed by more than 18 years $(22.9 \%), 3-6$ years $(19.1 \%)$, less than one year $(15 \%)$ and $1-2$ years $(13 \%){ }^{9}$ Females constituted $68.6 \%$ of the study sample compared to males (31.4\%). These results were somehow consistent with those of a study conducted in Iran which also revealed a higher proportion of females $(53.4 \%)$ compared to males $(46.6 \%),{ }^{11}$ but they were inconsistent with the Korean study which showed a higher proportion of males (51.8\%) compared to females $(48.2 \%){ }^{9}$ With regard to the site of lesions, the study showed that $64.3 \%$ of the patients had a generalized lesion of atopic dermatitis, followed by trunk $(17.1 \%)$, face $(11.4 \%)$, and extremities $(7.1 \%)$. Compared to the Korean study, head and neck constituted $35 \%$ of the studied patients, upper extremities $(35 \%)$, lower extremities (25\%), and trunk (11\%). ${ }^{9}$ Our study revealed that the majority $(58.3 \%)$ of those aging less than two years had face lesions compared to $41.7 \%$ who had generalized lesions, and for those aging 2-15 years, $53.3 \%$ of them had generalized lesions compared to $26.7 \%$ with extremities lesions. While the majority $(74.4 \%)$ of the patients aging more than 15 years had generalized lesions and $23.31 \%$ of them had trunk lesions. These results were consistent with general concept of lesion site according to patient's age which states that the distribution patterns vary according to the patients' age; during the first 2 years of life, the diseased is more commonly involve the face and scalp, while in older children, the lesions are commonly found in the extremities. In adults, it is more generalized, but sometimes localized to areas like the hands. ${ }^{12}$ One of the major criteria in the diagnosis of atopic dermatitis is the existence of a family history of the disease, which is considered to be an important risk factor for atopic dermatitis. The study revealed that $54.3 \%$ of the patients had a positive family history of atopic dermatitis. Studies from a number of western countries have also found a positive family history of the disease in $53-80 \%$ of the studied patients. ${ }^{13,14}$ In a study conducted in Thailand on adults, $54.2 \%$ of the patients had a positive family history of the disease. ${ }^{15}$ Regarding the history of other atopic diseases among the studied patients, the study showed that $48.5 \%$ of them had a positive history of other atopic diseases, $11.8 \%$ had asthma, $67.6 \%$ allergic rhinitis, and $20.6 \%$ had both diseases. Compared to a study conducted in Turkey, $44.2 \%$ of patients had a positive history of other atopic diseases like asthma and allergic rhinoconjuctivitis. ${ }^{16}$ The study revealed that the patients, in general, had elevated both leptin level $(60 \%)$ and 
IgE level (64.3\%). These results were consistent with those of a case-control study conducted in Egypt, which revealed that the serum leptin level was significantly elevated among cases than healthy controls. ${ }^{17}$ In contrast, a study conducted by Nagel et al. revealed no significant associations between high leptin levels and the prevalence of the symptoms of atopic dermatitis. ${ }^{18}$ On another hand, our study also showed that there is a significant association between high leptin level and high IgE level since $75.6 \%$ of the patients who had high leptin level also had a high IgE level. While a study conducted in Egypt revealed that the serum leptin level was inversely correlated with the serum IgE level and that this correlation was statistically significant. ${ }^{19}$

\section{Conclusion}

Atopic dermatitis affects a wide range of age groups, and different age categories have different sites of the lesion. Family history is a prominent diagnostic criterion of the disease. Almost half of the patients had a history of other atopic diseases like asthma and allergic rhinitis. Clinically, lichenification is more common among older age groups compared to the eczematous lesion, which is more common among younger age groups. Both leptin and IgE levels were high in most of the patients, and in about three quarters of the patients high leptin level was significantly associated with high $\operatorname{lgE}$ level. Further studies need to be conducted focusing on the association between obesity and atopic dermatitis and the relation of high leptin level with the severity of the disease.

\section{Competing interests}

The authors declare no competing interests.

\section{References}

1. Thomsen SA. Atopic dermatitis: natural history, diagnosis and treatment. ISRN Allergy 2014; 2014:354250.

2. Bieber T. Mechanisms of disease atopic dermatitis. N Engl J Med 2008; 358(14):1483-94.
3. Cork MJ, Danby SG, Vasilopoulos Y, Hadgraft J, Lane ME, Moustafa M, et al. Epidermal barriers dysfunction in atopic dermatitis. $\mathrm{J}$ Invest Dermatol 2009; 129(8):1892-908.

4. Asher MI, Montefort S, Bjerksten B, Lai CKW, Strachan DP, Weiland SK, et al. Worldwide time trends in the prevalence of symptoms of asthma, allergic rhinoconjunctivitis, and eczema in childhood: ISAAC phases one and three repeat multicountry cross-sectional survey. Lancet 2006; 368:733-43.

5. Nutten S. Atopic dermatitis: Global epidemiology and risk factors. Ann Nutr Metab 2015; 66(Suppl 1):8-16.

6. Kim BS. Atopic dermatitis clinical presentation. Medscape 2017. (Accessed March 14, 2017, at https://emedicine.medscape.com/article/1049085 -clinical\#b2).

7. American Academy of Dermatology. Atopic dermatitis: diagnosis recommendations. (Accessed March 20, 2017, at https:// www.aad.org/practicecenter/quality/clinicalguidelines/atopic-dermatitis/diagnosis-andassessment).

8. Siegfried EC, Hebert AA. Diagnosis of atopic dermatitis: mimics, overlaps, and complications. J Clin Med 2015; 4(5):884-917.

9. Chu H, Shin JU, Park CO, Lee H, Lee J, Lee KH. Clinical diversity of atopic dermatitis: $A$ review of 5,000 patients at a single institute. Allergy Asthma Immunol Res 2017; 9(2):158-68.

10. Furue M, Chiba T, Takeuchi S. Current status of atopic dermatitis in Japan. Asia Pac Allergy 2011; 1:64-72.

11. Kalmarzi RN, Ataee P, Homagostar G, Tajik M, Shekari A, Roshani D, et al. Prevalence of atopic dermatitis symptoms among students in Kurdistan; a North-West province of Iran. Int J Pediatr 2016; 4(1):1205-14.

12. Leung DYM, Eichenfield LF, Boguniewicz M. Atopic Dermatitis (Atopic Eczema). In: Goldsmith LA, Katz SI, Gilchrest BA, Paller AS, Leffell DJ, Wolff $\mathrm{K}$ editors. Fitzpatrick's Dermatology in General Medicine. $8^{\text {th }}$ ed. New York: Mc Graw Hill Medical; 2012. P. 165-81.

13. Wananukul S, Chatproedprai S, Tempark T, Phuthongkamt $W$, Chat-chatee $P$. The natural course of childhood atopic dermatitis: a retro-spective cohort study. Asian Pac J Allergy Immunol 2015; 33:161-8.

14. Pyun BY. Natural history and risk factors of atopic dermatitis in children. Allergy Asthma Immunol Res 2015; 7:101-5.

15. Kulthanan $K$, Samutrapong $P$, Jiamton $S$, Tuchinda P. Adult-onset atopic dermatitis: a cross-sectional study of natural history and clinical manifestation. Asian Pac J Allergy Immunol 2007; 25:207-14.

16. Yazganoglu KD, Ozkaya E. Non-typical morphology and localization in Turkish atopic dermatitis patients with onset before the age of 
The pattern of atopic dermatitis in a group .......

Zanco J. Med. Sci., Vol. 23, No. (3), December, 2019

https:// doi.org/ 10.15218/ zjms.2019.050

18 years. Indian J Dermatol Venereol Leprol 2011; 77(1):23-7.

17. Mohamed SA, Alsayad T, El-Askary A, Alwafa HA. Serum leptin level among school children with atopic dermatitis. Neonat Pediatr Med 2017; 3:130-6.

18. Nagel G, Koenig W, Rapp K, Wabitsch M, Zoellner I, Weilad SK. Associations of adipokines with asthma, rhinoconjunctivitis, and eczema in German schoolchildren. Pediatr Allergy Immunol 2009; 20:81-8.

19. Eldin LB, Algamal HA, El-Dory GF, Rashad M, El-Arab SE, Abo Al-ella NA, et al. Relation between obesity, lipid profile, leptine and atopic disorders in children. Egypt J Pediatr Allergy Immunol 2008; 6(1):27-34. 